\title{
A TEORIA DA AFILIAÇÃO: NOTAS PARA PENSAR A ADAPTAÇÃO DE NOVOS PÚBLICOS AO ENSINO SUPERIOR
}

\section{STUDENTS' AFFILIATION THEORY: NOTES TO THINK ABOUT THE ADAPTATION OF NEW PUBLICS TO HIGHER EDUCATION}

\author{
SAMPAIO, Sônia Maria Rocha \\ sonia.sampaio@terra.com.br \\ UFBA - Universidade Federal da Bahia \\ SANTOS, Georgina Gonçalves dos \\ georgina@ufrb.edu.br \\ UFRB - Universidade Federal do Recôncavo da Bahia
}

\begin{abstract}
RESUMO O conceito de afiliação do sociólogo francês Alain Coulon constitui uma utilização da etnometodologia aos processos intelectuais, institucionais e culturais que cercam a adaptação de estudantes à educação superior e é compreendido em três tempos distintos: do estranhamento, da aprendizagem e o tempo da afiliação. A consolidação dessa espécie de "profissão temporária" é crucial para a manutenção da condição estudantil de jovens em instituições dessa natureza. Este artigo apresenta e discute a utilidade do conceito de afiliação institucional e intelectual para que as universidades brasileiras, que vivem, desde 2008, importantes transformações em consequência da adesão ao Programa de Apoio a Planos de Reestruturação e Expansão das Universidades Federais (REUNI), otimizem seu funcionamento, desenvolvendo um sistema de gestão acadêmica capaz de acompanhar as exigências decorrentes da abertura da educação superior para novos públicos. Isso implica enfrentar, com novas estratégias, o abandono e o fracasso na educação superior. No plano humano, isso produz desmotivação, o medo do futuro, um déficit de formação e, frequentemente, menores chances de emprego num mundo extremamente competitivo, com consequências sobre a qualidade do nosso desenvolvimento como nação. Sobre o plano socioeconômico, os investimentos públicos tornam-se "não produtivos", ou seja, não repercutem, como deveriam, na redução das desigualdades e na inclusão das novas gerações no sistema produtivo e de serviços.
\end{abstract}

PALAVRAS-CHAVE: Afiliação. Educação superior. Etnometodologia. Formação. Gestão acadêmica.

ABSTRACT French sociologist Alain Coulon's concept of affiliation consists in the use of ethnomethodology in the analysis of intellectual, institutional and cultural processes implied in students' adaptation to higher education, which is understood as involving three different moments: unfamiliarity, learning and affiliation. The consolidation of this kind of "temporary profession" is crucial for the stability of youngsters' condition as students at this level of education. This paper presents and discusses the usefulness of the concept of institutional and intellectual affiliation in 
the case of Brazilian universities that are experiencing, since 2008, important changes as a consequence of the adhesion to Programa de Apoio a Planos de Reestruturação e Expansão das Universidades Federais (REUNI - Support Program for Federal Universities' Restructuration and Expansion Plans), to optimize their functioning through the development of management systems able to attend the requirements resulting from the increased access of new publics to higher education. This implies the need of new strategies to face abandon and failure in higher education. At the human level, it produces discouragement, fear of the future, educational deficit and, often, less employment opportunities in an extremely competitive world, with implications for the quality of our development as a country. At the socioeconomic level, public investments become "non productive", that is, do not present the expected repercussions on the reduction of inequalities and on the inclusion of new generations in the productive system and in the provision of services.

KEYWORDS: Academic Management. Affiliation. Ethnomethodology. Higher education.

\section{INTRODUÇÃO}

As universidades brasileiras estão confrontadas ao imenso desafio de ampliar a participação de amplos setores da juventude na educação superior. Demanda contemporânea incontornável, o prolongamento dos estudos entre a população jovem é uma tarefa a ser assumida com alta prioridade.

A necessidade de expansão do ensino superior continua na ordem do dia, pois a meta do Plano Nacional de Educação (PNE) em 2001, de alcançar pelo menos $30 \%$ dos jovens de 18 a 24 anos no ensino superior até $2011^{1}$, está longe de se concretizar, como comprova o Censo da Educação Superior 2010 (INEP, 2012, p. 35) e o Tribunal de Contas da União (BRASIL, 2009, p. 21). Segundo o Censo da Educação Superior, em 2009, a taxa de escolarização bruta ${ }^{2}$ passou de $15,1 \%$ em 2001 para 26,7\% em 2009 e a líquida ${ }^{3}$, de 8,9\% em 2001 para 14,4\% em 2009. Considerando também os jovens de 18 a 24 anos, graduados ou fora das escolas, 0 percentual passa para $17,2 \%$, em 2009 , ainda muito distante dos $30 \%$ projetados.

\footnotetext{
1 Dados ainda não disponíveis. O Censo da Educação Superior publicado em 2012 se refere ao Censo de 2010.

2 Taxa de escolarização bruta indica o número total de alunos matriculados na educação superior.

3 Taxa de escolarização líquida indica o total de matriculados na educação superior que estão na faixa de 18 a 24 anos.
} 
Colocar o Brasil em condições comparáveis a de outros países, mesmo aqueles da América Latina, exigirá um enorme esforço governamental e, especialmente, dos trabalhadores da educação superior: professores, técnicos e gestores. Esse movimento, iniciado há cerca de cinco anos em nosso país, abre-se para a entrada, na educação superior, de jovens oriundos de escolas públicas, cuja socialização e cultura são especialmente desconhecidas pelo mundo acadêmico, colocando novas questões pedagógicas, gerenciais e de suporte a sua permanência.

Tão importante quanto a ampliação de vagas, acompanhar o percurso desses estudantes até a conclusão da formação universitária com sucesso é uma questão crucial que diz respeito ao uso adequado dos recursos públicos e o atingimento dos objetivos de formação requeridos para a vida produtiva, com acesso garantido aos bens culturais, em uma sociedade baseada no conhecimento.

Numa perspectiva contemporânea, a gestão de instituições de educação superior requer uma aproximação da área pedagógica para informar e, eventualmente, direcionar suas políticas. Como resultado, o que se espera, além de uma evolução das estatísticas indicadoras de inclusão do sistema público de educação superior, é a redução significativa da taxa de inconclusão dos cursos por diferentes motivos, quando estudantes deixam a universidade sem um diploma e adiam, para um futuro incerto, sua formação superior. O preenchimento de vagas e utilização da infraestrutura ociosa oportuniza a incorporação, no ambiente acadêmico, de diferentes candidatos à formação universitária, de qualquer origem social e racial, propiciando condições para a plena aderência de novos segmentos de brasileiros à educação superior.

A compreensão do perfil dos estudantes, o acompanhamento de seu percurso universitário e a avaliação dos seus resultados são medidas que se inscrevem como prioridade nas políticas de gestão adotadas pelas universidades no âmbito do programa Apoio à Reestruturação e Expansão das Universidades Públicas Federais (REUNI), instituídas pelo governo federal em 2007. Essa aproximação entre instâncias gestoras e a área propriamente pedagógica da educação superior necessita, entretanto, de ferramentas tanto teóricas quanto práticas para se materializar. Esse artigo apresenta o conceito de afiliação, desenvolvido pelo 
sociólogo francês Alain Coulon (1995a; 1995b; 2008), apontando seu potencial de auxiliar o acompanhamento pedagógico dos estudantes e propor medidas institucionais que facilitem sua permanência.

\section{CONCEITO DE AFILIAÇÃO}

Na obra Etnometodologia e Educação, Coulon (1995a) já apresenta algumas noções sobre o conceito de afiliação que, nesta edição, foi traduzida como filiação. O interesse do autor por este conceito se dá a partir de uma pesquisa, desenvolvida por ele, sobre a entrada dos estudantes na vida universitária francesa. Coulon (1995a) destaca referências centrais para a elaboração desse conceito, como a noção de habitus de Bourdieu e a noção de membro utilizada por Harold Garfinkel. As ideias defendidas por esses autores fundamentam o conceito desenvolvido por Alain Coulon que deu origem ao livro $A$ condição de estudante: a entrada na vida universitária, traduzido para o português em 2008.

Ainda em Etnometodologia e Educação, Coulon (1995a) mostra uma clara associação entre afiliação e a noção de membro. Para esse autor, o estudante afiliado é aquele cuja competência torna-se uma rotina, que possui todas as características de um membro e que desenvolve as tarefas acadêmicas sem estranhamento. A afiliação implica em deixar de pensar no que se está fazendo e simplesmente conseguir desenvolver ações cotidianas de forma "automática". Em seu livro $A$ condição de estudante, Coulon amplia sua definição e afirma que a afiliação é o método pelo qual as pessoas adquirem um novo status social. Assim, podemos pensar na noção de afiliação como um processo contínuo, que se repete ao longo da vida do sujeito, cada vez que se coloca para ele a tarefa de tornar-se membro de um novo grupo, assimilar novas funções e desenvolver habilidades antes desconhecidas.

Da mesma forma que o sujeito mobiliza-se para novas aprendizagens, ele também carrega, em parte, um antigo habitus, indicando que as pessoas tendem a reproduzir um sistema de condições objetivas no interior do qual se formam como sujeitos sociais. Coulon (1995a, p. 156) ressalta, no entanto, que: 
[...] a sociologia dos habitus de P. Bourdieu dá conta das condições estruturais que pesam sobre essa passagem, em compensação, não chega a mostrar como ela se efetua concretamente, nem quais formas assume a objetivação prática dos atores que efetuam tal passagem.

O que interessa à compreensão do processo de afiliação é o modo como os atores desenvolvem determinadas tarefas ao se depararem com um novo contexto, como elaboram as ações no grupo, a fim de conseguirem se tornar membros.

Coulon (2008), na sua construção teórica do conceito de afiliação, utiliza-se também da ideia de passagem, que é como o antropólogo Van Gennep (2011) compreende as transições ritualísticas em que um indivíduo muda de status dentro de seu grupo, sugerindo um processo em três etapas consecutivas: separação, transição e incorporação. Em a "A Condição de Estudante", Coulon descreve as fases identificadas nos estudantes que observou como "tempos": o tempo do estranhamento, o tempo da aprendizagem e o tempo da afiliação. Assim, longe de constituir-se como fato natural, evidente ou espontâneo, o estatuto de estudante requer esforço, assemelhando-se à aprendizagem de um novo ofício e, de certo modo, de um jogo sofisticado em meio às regras e aos conhecimentos característicos da vida universitária.

A passagem para a universidade ainda solicita do jovem que organize três aspectos fundamentais do seu cotidiano: o tempo - é preciso compreender que as aulas não têm mais a mesma duração, que o volume e o tipo de trabalho a ser realizado demandarão um maior esforço intelectual e uma melhor organização; o espaço - dar-se conta de que a estrutura de uma universidade é consideravelmente maior do que a de uma escola de ensino médio e, por isso, é fundamental aprender a localizar os locais que frequentarão cotidianamente (departamentos, secretarias, bibliotecas); e a sua relação com o saber - em que devem desenvolver a capacidade de interpretação das normas institucionais, exigências e expectativas dos professores, porque não dominá-las gera ignorância em relação a uma quantidade desconhecida de situações problemáticas que eles serão instados a solucionar (COULON, 2008).

"A primeira tarefa que um estudante deve realizar quando chega à universidade é aprender o ofício de estudante" (COULON, 2008, p. 31). Dessa forma, o autor entende que ser estudante é resultado de um longo trabalho e 
aprendizado, sendo tarefa imprescindível na adoção desse novo papel pelo jovem. Essa compreensão o conduziu a pesquisar os mecanismos e as conexões internas desse processo de seleção e classificação social, que distingue aqueles que permanecerão estudantes daqueles que serão excluídos. Essa é a tese de Coulon: os que não conseguem fazer a passagem do estatuto de aluno do ensino médio ao de estudante universitário fracassam ou terão seu sucesso acadêmico comprometido. Esses estudantes serão eliminados ou se autoeliminarão porque não conseguiram se tornar membros desse novo grupo, permanecendo, portanto, estrangeiros. Coulon (2008) ainda distinguirá duas modalidades de afiliação: afiliação intelectual e afiliação institucional.

A afiliação intelectual é entendida como a aprendizagem das regras do uso, da construção, da reprodução e da exibição do conhecimento, como, por exemplo, saber quando e como falar ou se calar; apropriar-se do vocabulário particular de palavras eruditas; autorizar-se a pensar, a ler, a escrever considerando que todas essas operações e produções têm muita importância; desenvolver a concentração como um objeto de aprendizagem técnica; saber exibir sua competência; aprender a trabalhar intelectualmente por conta própria; saber decifrar as tarefas implícitas da universidade; ou mesmo saber usar uma biblioteca.

As três atividades que fundam a afiliação intelectual são: ler, escrever e pensar. Elas são, frequentemente, consideradas difíceis pelos estudantes e isso ocorre por conta da autonomia que lhes é atribuída para gerenciar sua própria vida acadêmica, fazendo com que eles não percebam a quantidade de investimento necessário para dar conta da dimensão intelectual da sua nova condição. $O$ verdadeiro desafio é ir além das avaliações semestrais, quando são chamados para mostrar suas competências em temas específicos, demonstrando ter atingido o conhecimento em seu conteúdo fundamental. Neste sentido, a afiliação intelectual é o processo pelo qual os estudantes passam a compreender, por antecipação, aquilo que lhes será solicitado academicamente (COULON, 2008).

De modo semelhante, a afiliação institucional é considerada bem sucedida quando o estudante consegue interpretar, usar e jogar com as regras da instituição, descobrir aquelas que estão escondidas e utilizá-las na construção individualizada de seu percurso. Corine, uma das estudantes entrevistadas por Coulon (2008, p. 
208), diz: "ser afiliada significa que conhecemos os mecanismos, sabemos como as coisas acontecem e quando não passamos três horas procurando uma secretaria ou um gabinete, quando não estamos enlouquecidos, quando cumprimos os prazos".

Afiliar-se é empreender, no momento certo, alguns trâmites que cadenciam a vida universitária: matricular-se nos cursos, elaborar e entregar trabalhos no prazo estabelecido e, finalmente, "[...] ter entendido o ritmo próprio das múltiplas regras da vida de um estudante e compreender sua ordem temporal." (COULON, 2008, p. 208). O estudante afiliado institucionalmente é aquele que compreende e está apto a seguir as normas da instituição, seu funcionamento e seus prazos, embora nem sempre seja a obediência o que mais revela o estado de sua afiliação. Eventualmente, por já compreender os modos do funcionamento institucional, o estudante exerce sua condição desjogando as regras estabelecidas, dentro de uma zona sem risco para o seu futuro.

Para Malinowski (2008), a noção de afiliação é extremamente frutífera por levar em consideração tanto as dimensões subjetivas, como as dimensões simbólicas da relação que os estudantes desenvolvem com a vida universitária. Este autor salienta também que a definição de afiliação, desenvolvida por Coulon (2008), deve abranger não apenas o conhecimento explícito das regras, mas sua reinterpretação e apropriação como um novo atributo de competência do estudante.

A conclusão satisfatória de um curso de graduação requer este processo de afiliação, que deve ocorrer nesses dois âmbitos: o intelectual e o institucional. $O$ fracasso de um tipo de afiliação irá provocar consequências no equilíbrio movente dessas adaptações a um novo mundo.

Carneiro (2010) numa pesquisa qualitativa realizada entre estudantes universitários de cursos de alto prestígio e que entraram na Universidade Federal da Bahia (UFBA) através da política de ação afirmativa, estudou como esses jovens lidavam com as situações vinculadas à sua permanência na universidade, considerando as condições educacionais e financeiras adversas características de sua história. Dois dos objetivos dessa pesquisa diziam respeito, diretamente, à afiliação institucional e intelectual.

Primeiro, a pesquisadora quis saber como eles lidavam com as normas e regras da universidade, com o funcionamento específico do ensino superior, e o 
outro objetivo era compreender as ações engendradas pelos sujeitos relativas ao conteúdo das disciplinas - apresentação de trabalhos, realização das provas, elaboração de projetos individuais e em grupo etc. Os outros objetivos estavam voltados para as questões financeiras, ou seja, como os estudantes conseguiam custear as despesas associadas a sua permanência e como se dava sua aproximação e convivência como outros atores do ambiente acadêmico: colegas, professores e funcionários, entendendo de forma mais aprofundada a natureza dessas relações.

Em que pese a importância do suporte financeiro para a permanência desse novo público universitário, esse estudo indica que estabelecer relações afetivas e redes de apoio dentro do ambiente acadêmico, ou outros a ele relacionados, irá impactar positivamente o processo de afiliação, tanto intelectual como institucional, descrito por Coulon (1995b; 2008). Embora haja outras dinâmicas envolvidas na questão da permanência do estudante universitário, todas elas irão desembocar no processo de afiliação, seja ele intelectual ou institucional.

Essas outras dinâmicas são principalmente de natureza singular, no âmbito das relações com a família ou com outros estudantes, e formam os "arquipélagos de certeza" (MORIN, 2000) que asseguram ao jovem parte da sua inserção institucional e intelectual na universidade. Para esse autor, dentre os "arquipélagos de certeza", há um oceano de incertezas, situações imprevisíveis a serem combatidas com estratégias eficientes.

São exatamente essas estratégias, que interessam à gestão universitária porque elas podem ser facilitadas ou mesmo promovidas institucionalmente, aumentando as chances de que os estudantes concluam sua formação com sucesso. Se o estudante se movimenta adequadamente frente a essas contingências intelectuais, acadêmicas, relacionais, afetivas e normativas, sua afiliação será impulsionada, estando o estabelecimento de uma rede relacional profundamente ligado à aprendizagem do modo de funcionamento da vida universitária.

\section{DOS POSSÍVEIS USOS DO CONCEITO DE AFILIAÇÃO}


Um dos indicadores utilizados para realizar a avaliação de uma instituição de educação superior é a sua taxa de evasão. Quanto menor for esta taxa, mais diplomados são disponibilizados à sociedade. Se os índices de evasão são consideráveis, podemos concluir que existem problemas e disfuncionamento, sem, contudo, podermos afirmar, no caso deles serem baixos, que tudo ocorre de forma satisfatória.

Na tentativa de compreender a evasão em universidades, uma das vertentes analisa o tema enfatizando a falência do preparo anterior dos estudantes para as exigências da vida acadêmica. Esta pode ser apenas uma via fácil diante da complexidade que o tema nos apresenta. Com isso, não excluímos dessa análise, a formação imperfeita disponibilizada por escolas de nível médio, sejam elas públicas ou particulares.

O fato de as escolas médias privadas terem como foco, quase exclusivo, auxiliar os jovens a ultrapassar a barreira do vestibular, em cursos de progressão linear, resulta num preparo muito insuficiente em habilidades importantes, que deem suporte ao futuro estudante universitário do ponto de vista das exigências intelectuais que enfrentará nessa nova etapa. O exemplo prático para nossa constatação é que, mesmo treinados para passar a barreira do ingresso na universidade, os estudantes, em geral, enfrentam muitas dificuldades na produção de textos acadêmicos.

Em escolas públicas, ao menos na realidade que conhecemos (nordestina, baiana), além da oferta de uma educação qualitativamente deficitária, não se realizam esforços consistentes para promover a continuidade dos estudos (SAMPAIO; SANTOS, 2011), facilitada, no caso de nossas universidades, pelas políticas de ações afirmativas por elas adotadas.

São ainda muito elevados, no Brasil, os números relativos às taxas de evasão. A tabela a seguir apresenta a evolução das taxas de evasão para o setor público e o privado, de 2002 até 2008, último ano disponível na sinopse do INEP:

Tabela I - Taxa de evasão anual em Universidades Públicas e Universidades Privadas, entre 2002 e 2008.

\begin{tabular}{l|l|l|l|l|l|l|l}
\hline Taxa Evasão & 2002 & 2003 & 2004 & 2005 & 2006 & 2007 & 2008 \\
\hline
\end{tabular}


Atos de Pesquisa em Educação - ISSN 1809-0354

Blumenau, v. 10, n.1, p.202-214, jan./abr. 2015

DOI: http://dx.doi.org/10.7867/1809-0354.2015v10n1p202-214

\begin{tabular}{l|l|l|l|l|l|l|l}
$\begin{array}{l}\text { Universidade } \\
\text { Pública }\end{array}$ & $25 \%$ & $27 \%$ & $23 \%$ & $37 \%$ & $41 \%$ & $45 \%$ & $42 \%$ \\
\hline $\begin{array}{l}\text { Universidade } \\
\text { Privada }\end{array}$ & $42 \%$ & $46 \%$ & $56 \%$ & $52 \%$ & $55 \%$ & $54 \%$ & $52 \%$ \\
\hline
\end{tabular}

Fonte: INEP, 2012

De forma geral, segundo esses dados, as universidades públicas encontramse em melhor situação que as de caráter privado no período observado. Entretanto, mesmo nessas instituições, o problema pode ser considerado grave e apresenta uma tendência a evoluir, ainda que, em 2008, observe-se uma ligeira queda em relação ao ano anterior, em ambas as dependências administrativas.

Esse desperdício humano e de recursos precisa ser enfrentado pelas universidades, mas, para fazê-lo, precisamos compreender o que realmente acontece e desenvolver ferramentas metodológicas adequadas ao enfrentamento do fenômeno que ocorre em escala mundial, considerando ainda que certo percentual de perda será inevitável. Para citar um exemplo, países como a Suiça, há vinte anos, decidiram enfrentar este problema, tomaram medidas no sentido de diminuir o fracasso, especialmente, no primeiro ano e, em alguns anos, reduziram a taxa de fracasso que era de 45\%, mas que ainda se situa em 20\% (COULON, 2012, 2013).

Assim, espera-se uma rentabilidade dos investimentos em educação, tema sobre o qual nós apenas começamos a pensar no Brasil. É mais comum considerarmos a luta contra o fracasso e o abandono dos estudos, em qualquer nível da educação, "em termos humanistas e pelo viés da generosidade, mas é necessário também fazer contas" (COULON, 2012, p. 24).

No caso brasileiro, além da seleção oficial para a entrada na educação superior, seja através de exames vestibulares ou através do Exame Nacional do Ensino Médio (ENEM), outra seleção, ou talvez outras, operam de forma oficiosa. Essas seleções referem-se à organização dos currículos; ao fato de não haver nas famílias outras experiências de pais ou filhos universitários; à hierarquia socialmente estabelecida entre os diferentes tipos de diplomas concedidos pelas universidades; às dificuldades encontradas pelos estudantes para responder, de forma adequada,

\footnotetext{
${ }^{4}$ Existem, no Brasil, 190 universidades, 101 públicas e 89 privadas. Funcionam ainda 126 centros universitários, em sua grande maioria privados, e 2.025 Faculdades igualmente quase todas privadas. Um total de 911.739 estudantes ingressou em universidades, em 2010: 60,1\% em universidades privadas e $39,9 \%$ no sistema público.
} 
às exigências dos professores; às competências voltadas para as tarefas intelectuais efetivamente conquistadas antes da entrada na universidade e a aspectos biográficos concorrentes, como casamento e filhos, especialmente para estudantes do sexo feminino, e trabalho, para ambos os sexos.

Além da perspectiva macro de análise em torno da evasão, é possível abrir as lentes da observação para encontrar, em detalhes do cotidiano da vida em universidades, se não motivos, mas condições sutis que, reunidas, fazem parte do percurso até o abandono completo dos estudos. A organização universitária é, em grande parte, implícita, o que dá aos primeiros passos dentro da universidade o aspecto de uma corrida de obstáculos na qual sobrevivem apenas os mais dotados, do ponto de vista escolar, e aqueles que conseguem decodificar, antes dos outros, a coerência geral da instituição e do currículo (FELOUZIS, 1997, p. 94).

Além disso, quando falamos em evasão ou fracasso ou ainda de abandono, é provável que cada uma dessas palavras designe fenômenos diferentes dentro de um mesmo campo. Precisamos enfrentar essa discussão e, dessa forma, permitir que a pesquisa avance.

Sendo assim, para o novo público que chega às nossas instituições públicas de educação superior, resultando do processo de ampliação de vagas e interiorização, diferentes fatores desfavoráveis interagem colorindo o seu processo de afiliação à universidade, descrito por Alain Coulon. Não fazemos aqui um prognóstico sombrio para o futuro acadêmico desses jovens, bem ao contrário. Somos testemunhas da tenacidade com que eles se apegam ao que consideram "uma oportunidade única" em suas vidas.

O processo de afiliação se dá para todos os estudantes e não apenas para aqueles cujas histórias pessoais e escolares são particularmente difíceis. Mas é correto afirmar que as experiências desse público específico podem ser muito exigentes, como aponta o estudo de Carneiro (2010) e solicitar, dos novos ingressos, estratégias inusitadas.

Levar em conta as dificuldades postas para os novos estudantes pode resultar em medidas até simples de acolhimento, acompanhamento e orientação, mas que, para serem adotadas, necessitam de postura firme, decisão de caráter institucional e comprometimento da comunidade docente. A orientação acadêmica 
se constituiu como estratégia privilegiada dos estudos pós-graduados, talvez pela naturalização da relação diádica que se estabelece entre orientador e orientando na construção do trabalho de pesquisa. Ao contrário, na graduação, sabe-se da dificuldade que apresentam os docentes de exercer essa função que consideram espúria às suas funções.

A orientação acadêmica, compreendida como espaço para aprendizagem e partilha de impressões, dúvidas, sentimentos, pode se constituir como uma tecnologia educacional eficiente para dar conta e auxiliar os novos estudantes a finalizar seu processo de afiliação.

O abandono dos estudos é um objeto privilegiado da pesquisa sobre a universidade contemporânea, pela simples constatação de sua amplitude. Para Coulon (2008, p. 31), “Hoje o problema não é entrar na universidade, mas continuar nela [...]", referindo-se à gravidade da situação que atinge sistemas universitários em todo o mundo.

\section{SONNIA MARIA ROCHA SAMPAIO}

Professora Associada IV do Instituto de Artes, Humanidades e Ciências Prof. Milton Santos (IHAC) da Universidade Federal da Bahia -UFBA. Foi Coordenadora de Ações Afirmativas, Educação e Diversidade da Pró-Reitoria de Assistência Estudantil da UFBA. Coordena o Programa de Pós-Graduação Estudos Interdisciplinares sobre Universidade - UFBA.

\section{GEORGINA GONÇALVES DOS SANTOS}

Professora Adjunta II da Universidade Federal do Recôncavo da Bahia e diretora do Centro de Artes, Humanidades e Letras (UFRB). Doutorado em Sciences de L'Éducation - Université de Paris VIII. Professora do Programa de Pós-Graduação Estudos Interdisciplinares sobre a Universidade -UFBA.

\section{REFERÊNCIAS}

BRASIL. Tribunal de Contas da União. Relatório de auditoria operacional: Programa Universidade para Todos (ProUni) e Fundo de Financiamento ao Estudante do Ensino Superior (FIES) / Relator Ministro José Jorge. - Brasília: TCU, 2009.

CARNEIRO, A. S. C. Caminhos universitários: a permanência de estudantes de origem popular em cursos de alto prestígio. 2010. 102 p. Dissertação (Mestrado em Psicologia) - Universidade Federal da Bahia, Salvador. 
Atos de Pesquisa em Educação - ISSN 1809-0354

Blumenau, v. 10, n.1, p.202-214, jan./abr. 2015

DOI: http://dx.doi.org/10.7867/1809-0354.2015v10n1p202-214

COULON, A. Etnometodologia. Petrópolis: Vozes, 1995a, 136 p.

. Etnometodologia e educação. Petrópolis: Vozes, 1995b, 205 p.

. A condição de estudante: a entrada na vida universitária. Salvador:

EDUFBA, 2008, 276 p.

O sucesso estudantil e sua avaliação: que política universitária é possível? In: SANTOS, G.; SAMPAIO, S. (orgs.) Observatório da Vida Estudantil. Estudos sobre a vida e cultura universitárias. Salvador: EDUFBA, pp. 19-30, 2012.

Universidade e Respondabilidade Social. In: SANTOS, G.; SAMPAIO, S. (orgs.) Observatório da Vida Estudantil. Universidade, responsabilidade social e juventude. Salvador: EDUFBA, p. 313-318, 2013.

FELOUZIS, G. Les Étudiants et la sélection universitaire. Revue Française de Pédagogie, n. 119, p. 91-106, 1997.

INSTITUTO NACIONAL DE ESTUDOS E PESQUISAS EDUCACIONAIS ANÍSIO TEIXEIRA. Censo da Educação Superior: 2010 - resumo técnico. Brasília: INEP, 2012.

MALINOWSKI, N. Diferenciación de los tiempos estudiantiles e impacto sobre el proceso de afiliación en México. Revista Latinoamericana de Ciencias Sociales, Niñez y Juventud, Manizales, v. 6, n. 2, p. 801-819, 2008.

MORIN, E. Os Sete Saberes necessários à Educação do Futuro. São Paulo: Cortez; Brasília: UNESCO, 2000, 102 p.

SAMPAIO, S.; SANTOS, G. Vincular a universidade a escolas de ensino médio. Apontamentos iniciais para uma tarefa urgente. Revista Estudos IAT, v. 2, p. 12-20, 2011.

VAN GENNEP, A. Rituais de Passagem. Petrópolis: Vozes, 2011, 168 p. 